\title{
MANFAAT AROMATERAPI JASMINE SAMBAC DALAM MENINGKATKAN LIBIDO PADA AKSEPTOR SUNTIK DMPA
}

\author{
Isy Royhanaty, Boediarsih, Mualifah \\ STIKes Karya Husada Semarang, Jl. Kompol R. Soekanto No. 46 Semarang \\ royhanatyisy@gmail.com
}

\begin{abstract}
ABSTRAK
DMPA (Depo-Medroxy Progesterone Acetate) adalah kontrasepsi suntik hormonal yang banyak dipakai masyarakat, dengan salah satu efek samping adalah penurunan libido. Hasil wawancara langsung dengan 10 akseptor suntik DMPA, 80\% menyatakan nyeri saat berhubungan seksual dengan pasangan, sehingga menyebabkan gairah seksual menurun. Salah satu cara mengatasinya adalah dengan menggunakan aromaterapi jasmine sambac. Penelitian ini bertujuan untuk mengujicobakan aromaterapi jasmine sambac untuk meningkatkan libido pada akseptor suntik DMPA di PMB Aini Kabupaten Kudus. Jenis penelitian ini adalah quasi experiment dengan desain one group pre-test and post-test without control. Sampel dalam penelitian ini adalah 16 akseptor suntik DMPA yang diambil dengan teknik purposive. Responden menggunakan aromaterapi jasmine sambac dalam bentuk lilin pada malam hari menjelang tidur, dengan durasi 2,5 jam selama 14 hari. Tingkat libido diukur menggunakan kuesioner FSFI. Analisa data menggunakan uji Wilcoxon. Rata-rata responden mengalami peningkatan total tingkat libido sebesar 15,8 point. Rata-rata peningkatan perdomain aspeknya adalah keinginan 2,3 point, gairah 2,5 point, lubrikasi 2,6 point, orgasme 2,8 point, kepuasan 2,5 point, dan nyeri 3,2 point dengan $p$ value 0,000 . Aromaterapi jasmine sambac berpengaruh signifikan dalam meningkatkan total libido, termasuk 6 domain aspeknya, rata-rata peningkatan yang paling banyak adalah pada domain nyeri, dan yang paling sedikit rata-rata peningkatnnya pada domain gairah.
\end{abstract}

Kata Kunci : aromaterapi; jasmine sambac; libido; akseptor DMPA

\section{BENEFITS OF JASMINE SAMBAC AROMATERAPY IN INCREASING LIBIDO IN DMPA INJECTION ACCEPTORS}

\begin{abstract}
Depo-Medroxy Progesterone Acetate is a hormonal injection contraceptive that is widely used by the community, with one of the side effects is a decrease in libido. The results of direct interviews with 10 DMPA injection acceptors, $80 \%$ stated pain during sexual intercourse with a partner, causing decreased sexual arousal. One way to overcome this problem is to use jasmine sambac aromatherapy. Destination. This study was to measure the effectiveness of jasmine sambac aromatherapy to increase libido in DMPA injection acceptors at Aini Maternal Health Clinic, Kudus Regency. This type of research was a quasi experiment with one group pre-test and post-test designs without control. The sample in this study were 16 DMPA injection acceptors taken by purposive technique. Respondents used jasmine sambac aromatherapy in the form of candles at night before bed, with a duration of 2.5 hours for 14 days. Libido level was measured using the FSFI questionnaire. Data analysis using the Wilcoxon test. The average of respondents experienced an increase in the total level of libido by 15.8 points. The average increase in aspects per domain is 2.3 points of desire, 2.5 points of arousal, 2.6 points of lubrication, 2.8 points of orgasm, 2.5 points of satisfaction, and 3.2 points of pain. The results of the Wilcoxon test showed that there were significant differences in the level of total libido and all domain aspects ( $p$ value $\leq 0.05$ ). Jasmine sambac aromatherapy has a significant effect to increase of libido, including its 6 domain aspects, where the average increase is the most in the pain domain, and the least average increase is in the arousal domain.
\end{abstract}

Keywords: aromatherapy; jasmine sambac ; libido; DMPA acceptors. 


\section{LATAR BELAKANG}

Secara umum, di Indonesia terdapat dua jenis kontrasepsi, yaitu kontrasepsi hormonal dan kontrasespsi non hormonal. Salah satu kontrasepsi hormonal yang banyak dipakai masyarakat Indonesia adalah DMPA (Depo Medroxyprogesterone Acetate). DMPA adalah kontrasepsi hormon yang bisa diberikan secara disuntik (WHO, 2016). Kontrasepsi DMPA merupakan salah satu jenis kontrasepsi yang pemakaiannya luas dan meningkat (WHO, 2009).

Di Indonesia suntik DMPA merupakan jenis kontrasepsi yang paling banyak diminati yaitu sekitar 17.104.340 (47.78\%) dari seluruh peserta KB aktif sebanyak 35.795 .560 (75.10\%) pengguna. Berdasarkan data Badan Kependudukan dan Keluarga Berencana Nasional (BKKBN) pada bulan Desember 2018 peserta KB aktif di Jawa Tengah yang menggunakan kontrasepsi suntik sebanyak 564.35 (53.97\%) pengguna, sedangkan data profil kesehatan Kabupaten Kudus tahun 2018 menyatakan bahwa dari 83.36\% pengguna KB (Keluarga Berencana) hormonal terdapat 63.7\% pengguna konrasepsi suntik DMPA (SDKI, 2018).

Mengingat jumlah akseptor kontrasepsi suntikan semakin banyak, maka perlu diwaspadai dan antisipasi kemungkinan efek samping yang dapat terjadi. Efek samping yang sering ditemukan dari kontrasepsi suntikan DMPA adalah penambahan berat badan, gangguan haid, mual, mata berkunang-kunang, sakit kepala, penurunan libido, dan vagina kering (Royhanaty, 2017). Efek samping berupa vagina kering merupakan efek samping dari hormon progesterone. Kontrasepsi suntikan DMPA memiliki efek progesterone yang tinggi sehingga terjadi pengeringan pada vagina yang menyebabkan nyeri saat melakukan hubungan seksual. Nyeri saat berhubungan seksual dapat menimbulkan penurunan gairah atau disfungsi seksual pada wanita (Yosin et al., 2016).

Berdasarkan penelitian tentang hubungan lama pemakaian KB suntik DMPA dengan penurunan libido pada akseptor KB DMPA didapatkan hasil bahwa 45\% akseptor KB suntik DMPA mengalami penurunan libido yang cukup kuat (Damailia et al., n.d.).
Penurunan libido pada akseptor KB suntik, meskipun tidak dialami pada semua wanita tetapi tetap harus mendapat perhatian (Batlajery et al., 2015). Penurunan libido merupakan masalah yang serius dalam berhubungan dengan pasangan. Dampak langsung dari penurunan libido terhadap hubungan seksual, seperti ketidaknyamanan, perasaan tidak aman, dan rasa khawatir tidak mendapat perhatian dari pasangan yang membuat individu melakukan berbagai macam adaptasi seksual (Lestariningsih et al., 2017).

Hubungan seksual dalam keluarga merupakan puncak keharmonisan dan kebahagiaan, oleh karena itu kedua pihak harus dapat menikmati bersama. Ketidakpuasan seks dapat menimbulkan perbedaan pendapat, perselisihan, dan akhirnya bisa sampai berujung pada perceraian (Pratama \& Pusparini, 2019).

Penurunan libido dapat diatasi dengan berkonsultasi kepada dokter atau konselor. Cara lain yang dapat dilakukan untuk meningkatkan libido antara lain meditasi kesadaran penuh, terapi hormon, yoga, istirahat yang cukup, berkomunikasi dengan pasangan, dan membuat variasi dalam kehidupan seks (Annisa Aurum Mahardika, Sri Nadya Saanin, 2016).

Membuat variasi dalam kehidupan seks dapat dilakukan pada posisi, waktu, atau ruangan yang digunakan untuk berhubungan. Ruangan yang digunakan untuk berhubungan dengan pasangan biasanya masih kurang diperhatikan. Padahal ruangan juga dapat membawa pengaruh besar dalam meningkatkan libido. Ruangan yang terlihat bersih, rapi dan harum dapat meningkatkan kenyamanan berhubungan seksual dan meningkatkan libido. Salah satu cara membuat ruangan terasa nyaman adalah dengan memberikan aromaterapi (C.W. et al., 2010).

Tidak semua aroma dapat meningkatkan libido. Salah satu aroma yang terbukti dapat membangkitkan romantisme di kamar tidur adalah aromaterapi jasmine. Jasmine adalah jenis tanaman merambat, semak, perdu, dalam keluarga zaitun (oleanceae). Jenis jasmine ada sekitar 200 species. Tumbuhan asli daerah beriklim tropis dan hangat dari Euraia, Australia, dan Oceania. Jenis jasmine yang terkenal 
adalah melati putih (jasmine sambac). Jasmine juga dipakai sebagai bahan minuman seperti teh dengan berbagai varian., aromaterapi, skincare, atau kosmetik. Aroma jasmine terkesan feminime, lembut, dan romantis. Aroma jasmine juga selalu berkesan di hidung. Aroma khasnya dapat memberikan relaksasi pada otak sehingga mampu merangsang untuk meningkatkan libido. Kesan romantis dan hangat akan tercipta di dalam kamar ketika diberikan aromaterapi jasmine (Meyer, n.d.).

Aroma terapi terutama bekerja melalui indra penciuman. Indera penciuman yang merangsang ujung saraf terletak di belakang hidung yang nantinya akan mengalirkan rangsangan ke otak. Inilah yang disebut sistem limbic (Sagita \& Martina, 2020). Jasmine yang memiliki kandungan senyawa utama seperti linalool memiliki manfaat sebagai antidepresan. Aroma jasmine yang akan merangsang hormon serotonin sehingga mendorong energi dan meningkatkan suasana hati. Selain itu jasmine memiliki zat sedatif terhadap saraf otonom dan keadaan jiwa yang bersifat menenangkan tubuh, pikiran dan jiwa serta menciptakan energi positif (Putri et al., 2018)

Minyak esensial jasmine memiliki manfaat yang dapat merangsang kelenjar di bawah otak di mana kelenjar ini merupakan master dari kelenjar endokrin yang mengontrol produksi hormon. Aktifnya kelenjar bawah otak dapat menyebabkan dorongan seks menjadi rendah. Jadi, keberadaan minyak aromaterapi akan membantu menjaga kadar tersebut tetap stabil. Molekul-molekul minyak yang begitu kecil dapat berbaur dengan cepat dalam aliran darah dan mengalirkannya ke seluruh tubuh. Aroma alami yang hadir dalam minyak aromaterapi pun menjadi kunci penting untuk mendatangkan daya tarik seksual (Koensoemardiyah, 2010).

Aroma jasmine yang terhirup oleh hidung akan masuk ke dalam aliran darah dan cairan tubuh serta menimbulkan efek farmakologi yang alami bagi tubuh. Molekul (volatile) aroma jasmine yang terhirup akan sampai di sistem limbic otak (amigdala dan hipokampus) melalui transmisi oleh bulbus olfaktorius dan traktus olfaktorius sehingga akan memengaruhi saraf, dimana saraf simpatis yang bertugas mengatur ketegangan, kewaspadaan, dan keterjagaan yang akan menurun dan saraf parasimpatis akan bekerja dengan sekresi serotonin dan endorfine sehingga menyebabkan perasaan yang rileks, nyaman, dan lembut. Serotonin yang dihasilkan nuclei raphe yang terletak dibagian tengah pons dan medula, serotonin akan berperan sebagai inhibitor untuk membantu tubuh menjadi relaks. Hormon endorfin yang diproduksi oleh kelenjar pituitary menyebabkan perasaan yang tenang dan senang. Sistem limbic berfungsi untuk mengatur emosi dan perasaan, sehingga aroma jasmine yang lembut akan menyeimbangkan kondisi emosional sehingga akan menciptakan perasaan yang nyaman dan tenang dan akan meningkatkan libido (Sagita \& Martina, 2020).

Praktik Mandiri Bidan (PMB) Aini merupakan salah satu tempat yang memberikan pelayanan KB di Kabupaten Kudus. Hasil studi pendahuluan didapatkan 70\% akseptornya adalah suntik DMPA. Hasil wawancara langsung dengan 10 akseptor suntik DMPA, 8 diantaranya menyatakan nyeri saat berhubungan seksual dengan pasangan, sehingga menyebabkan gairah seksual mereka menurun. Penatalaksanaan yang telah dilakukan terhadap keluhan efek samping tersebut hanya dengan konseling.

Berdasarkan uraian diatas, maka penulis tertarik untuk melakukan peneitian dengan mengujicobakan aromaterapi jasmine sambac untuk meningkatkan penurunan libido akiat efek samping dari suntik DMPA di PMB Aini Kabupaten Kudus.

\section{METODE}

Penelitian ini termasuk penelitian kuantitatif. Jenis penelitian yang digunakan adalah quasi experiment dengan desain one group pre-test and post-test without control group. Penelitian ini dilakukan pada bulan Juli 2020 di PMB Aini Kabupaten Kudus. Penelitian ini sudah melalui uji etik dengan nomor ethical clearance 272/KH.KEPK/KT/IV/2020.

Populasi dari penelitian ini adalah semua akseptor suntik DMPA di PMB Aini Kabupaten Kudus sejumlah 50 akseptor (Data akseptor PMB Aini, Juli 2020). Teknik pengambilan 
sampel yang digunakan adalah purposive sampling, yaitu akseptor suntik DMPA aktif minimal 2 tahun terakhir, yang memiliki keluhan dalam berhubungan seksual, bersedia menjadi responden, berusia 20 - 35 tahun, menikah dan tinggal serumah bersama suaminya. Berdasarkan kriteria tersebut, maka didapatkan jumlah sample adalah 16 akseptor. Perlakuan dalam penelitian ini adalah dengan memberikan aromaterapi jasmine sambac dalam bentuk lilin yang digunakan pada malam hari menjelang tidur, dengan durasi 2,5 jam selama 14 hari.

Data penelitian yang diolah dalam penelitian ini adalah data primer berupa tingkat libido akseptor sebelum dan sesudah perlakuan, yang diukur menggunakan kuesioner FSFI (Female Sexual Function Index) yang sudah terstandar. Kuesioner FSFI mengukur 6 domain fungsi seksual, meliputi desire (keinginan), arousal (gairah), lubrication (lubrikasi), orgasm (orgasme), satisfaction (kepuasan), dan pain (nyeri). Data penelitian yang telah didapatkan, diolah dan dianalisis menggunakan statistic deskriptif dan disajikan dalam bentuk mean, median, nilai minimum, nilai maksimum, dan standar deviasi. Berikutnya data dianalisa menggunakan uji statistic Wilcoxon, setelah dilakukan uji normalitas data menggunakan Shapiro Wilk dan menghasilkan sebagian data tidak berdistribusi normal ( $p$ value $\geq 0,05$ ).

\section{HASIL}

Gambaran karakteristik responden pada penelitian ini meliputi umur dan lama penggunaan kontrasepsi DMPA. Penelitian ini melibatkan 16 responden. Gambaran umur dan lama penggunaan suntik DMPA responden dapat dilihat pada tabel 1 berikut ini.

Tabel 1. Karakteristik Responden ( $n=16)$

\begin{tabular}{|c|c|c|c|c|c|}
\hline Data & Mean & Median & Min & $\operatorname{Max}$ & SD \\
\hline Umur (tahun) & 31,0 & 31,0 & 25,0 & 35,0 & 3,2 \\
\hline $\begin{array}{l}\text { Lama } \\
\text { penggunaan } \\
\text { (tahun) }\end{array}$ & 4,7 & 4,5 & 3,0 & 7,0 & 1,1 \\
\hline
\end{tabular}

Tabel 1 menunjukkan bahwa rata-rata usia responden adalah 31 tahun dan rata-rata lama penggunaan suntik DMPA responden adalah
4,7 tahun. Gambaran pekerjaan responden dapat dilihat pada tabel 2 berikut ini.

Tabel 2. Gambaran Pekerjaan Responden $(n=16)$

\begin{tabular}{lcc}
\hline \multicolumn{1}{c}{ Pekerjaan } & Jumlah & Prosentase (\%) \\
\hline Karyawan pabrik & 9 & 56,3 \\
IRT & 5 & 31,3 \\
PNS & 1 & 6,3 \\
Pedagang & 1 & 6,3 \\
\hline Total & $\mathbf{1 6}$ & $\mathbf{1 0 0}$ \\
\hline
\end{tabular}

Tabel 2 menunjukkan bahwa sebagian besar responden bekerja sebagai karyawan pabrik dan sebagian kecil bekerja sebagai PNS dan pedagang. Hasil penelitian tingkat libido akseptor suntik DMPA sebelum dan sesudah menggunakan aromaterapi jasmine sambac dapat dilihat pada tabel 3 .

\section{Tabel 3. Pengaruh Aromaterapi Jasmine Sambac Terhadap Tingkat Libido Akseptor Suntik DMPA $(n=16)$}

\begin{tabular}{lcccccc}
\hline \multicolumn{1}{c}{ Variabel } & Mean & $\begin{array}{c}\text { Medi } \\
\text { an }\end{array}$ & Min & Max & SD & $P$ \\
\cline { 1 - 4 } $\begin{array}{l}\text { Keinginan } \\
\text { Pre }\end{array}$ & 2,2 & 2,4 & 1,2 & 3,6 & 0,9 & 0,000 \\
Post & 4,5 & 4,8 & 3,6 & 6,0 & 0,7 & \\
\hline Gairah & & & & & & \\
Pre & 2,0 & 2,1 & 1,2 & 3,6 & 0,8 & 0,000 \\
Post & 4,5 & 4,8 & 2,7 & 6,0 & 0,9 & \\
\hline Lubrikasi & & & & & & \\
Pre & 2,4 & 2,4 & 0,9 & 4,8 & 1,2 & 0,000 \\
Post & 5,0 & 5,4 & 3,4 & 6,0 & 0,8 & \\
\hline Orgasme & & & & & & \\
Pre & 2,3 & 2,4 & 0,8 & 4,8 & 1,1 & 0,000 \\
Post & 5,1 & 5,6 & 4,0 & 6,0 & 0,8 & \\
\hline Kepuasan & & & & & & \\
Pre & 2,5 & 2,4 & 1,2 & 4,8 & 1,1 & 0,000 \\
Post & 5,0 & 4,8 & 3,6 & 6,0 & 1,0 & \\
\hline Nyeri & & & & & & \\
Pre & 2,0 & 1,6 & 0,0 & 3,6 & 1,2 & 0,000 \\
Post & 5,2 & 5,6 & 3,6 & 6,0 & 1,0 & \\
\hline Total Pre & 13,5 & 14,3 & 6,6 & 23,2 & 5,8 & 0,000 \\
Total Post & 29,3 & 31,1 & 21,4 & 34,5 & 4,5 & \\
\hline & & & & & & \\
\hline
\end{tabular}

Tabel 3 menunjukkan bahwa rata-rata responden mengalami peningkatan total tingkat libido sebelum dan sesudah menggunakan aromaterapi jasmine yaitu sebesar 15,8 point. Selain peningkatan total tingkat libido, rata-rata responden juga mengalami peningkatan 
perdomain aspeknya. Peningkatan perdomain aspeknya adalah keinginan 2,3 point, gairah 2,5 point, lubrikasi 2,6 point, orgasme 2,8 point, kepuasan 2,5 point, dan nyeri 3,2 point. Dari ke enam domain aspek fungsi seksual, terlihat bahwa rata-rata peningkatan yang paling banyak adalah pada domain nyeri, dan yang paling sedikit rata-rata peningkatnnya adalah pada domain gairah. Hasil uji statistik tingkat libido akseptor suntik DMPA sebelum dan sesudah menggunakan aromaterapi jasmine sambac menggunakan uji Wilcoxon dapat dilihat pada tabel berikut ini. Tabel tersebut dapat terlihat bahwa ada perbedaan yang signifikan pada tingkat libido total dan semua domain aspeknya antara sebelum dan sesudah menggunakan aromaterapi jasmine sambac ( $p$ value $\leq 0,05$ ). Berdasarkan hasil tersebut dapat disimpulkan bahwa aromaterapi jasmine sambac berpengaruh signifikan dalam meningkatkan total libido, termasuk 6 domain aspeknya, pada akseptor suntik DMPA di PMB Aini Kabupaten Kudus.

\section{PEMBAHASAN}

Hasil penelitian didapatkan bahwa akseptor suntik DMPA yang lebih dari 2 tahun mengalami penurunan gairah seksual (libido). Masalah ini dapat mengganggu hubungan dan keharmonisan antar pasangan. Penilaian libido diperoleh dari hasil total nilai kuesioner FSFI, dimana terdapat 6 domain aspek yang dinilai, yaitu keinginan, gairah, lubrikasi, orgasme, kepuasan, dan nyeri.

Sebelum menggunakan aromaterapi jasmine, ada 3 dari domain aspek yang paling banyak dikeluhakan oleh responden, yaitu lubrikasi, kepuasan, dan nyeri. Pada masingmasing domain aspek tersebut, responden memberikan jawaban yang berbeda-beda. Pada domain aspek lubrikasi rata-rata jawaban responden adalah jarang ada lubrikasi (kurang dari setengah waktu). Pada domain aspek kepuasan rata-rata jawaban responden adalah agak tidak puas. Pada domain aspek nyeri ratarata jawaban responden adalah sering nyeri. $\mathrm{Hal}$ tersebut merupakan efek samping dari suntik DMPA telah lebih dari 2 tahun. Adanya lubrikasi yang kurang akan menyebabkan timbulnya nyeri saat berhubungan seksual, dan akhirnya akan mengurangi tingkat kepuasan hubungan seksual (Pratama \& Pusparini, 2019).

Salah satu efek samping dari penggunaan suntik DMPA jangka panjang adalah adanya penurunan libido. Hal ini timbul karena efek progestin dosis tinggi yang terdapat di suntikan DMPA akan menyebabkan perubahan siklus hormon alami wanita (Triloka Wulandari \& Januriwasti, n.d.). Selain hal tersebut, perubahan siklus hormon alami wanita ini juga akan menyebabkan keringnya vagina, sehingga berdampak kurangnya lubrikasi pada saat berhubungan seksual dan akan menyebabkan nyeri sanggama. Hal ini juga yang cenderung menyebabkan wanita malas melakukan hubungan seksual (Zettira \& Nisa, 2015).

$\mathrm{Hal}$ ini juga yang menyebabkan responden cenderung mengalami peningkatan kecemasan dalam hubungan seksual. Kecemasan, kelelahan, dan stress dapat menyebabkan seseorang mengalami penurunan gairah seksual. Stress menyebabkan seseorang menjadi tegang sehingga enggan untuk berhubungan seksual (Yosin et al., 2016).

Sesudah menggunakan aromaterapi jasmine sambac, terdapat peningkatan nilai FSFI, terutama pada 3 domain aspek yang sebelumnya menjadi keluhan responden, yaitu lubrikasi, kepuasan, dan nyeri. Pada domain aspek lubrikasi, yang sebelumnya rata-rata jawaban responden adalah jarang ada lubrikasi (kurang dari setengah waktu), sesudahnya meningkat menjadi sering ada lubrikasi (lebih dari setengah waktu). Pada domain aspek kepuasan yang sebelumnya rata-rata jawaban responden adalah agak tidak puas, sesudahnya meningkat menjadi sangat puas. Pada domain aspek nyeri yang sebelumnya rata-rata jawaban responden adalah sering nyeri sesudahnya menjadi jarang nyeri.

Hasil pelitian ini juga didapatkan bahwa ratarata responden mengalami peningkatan total tingkat libido sesudah menggunakan aromaterapi jasmine. Selain itu juga didapatkan bahwa rata-rata responden juga mengalami peningkatan perdomain aspeknya, dimana dari 6 domain aspek fungsi seksual, rata-rata peningkatan yang paling banyak adalah pada 
domain aspek nyeri, dan yang paling sedikit rata-rata peningkatnnya adalah pada domain aspek keinginan. Setelah dilakukan uji statistik menggunakan Wilcoxon, didapatkan bahwa ada perbedaan yang signifikan pada tingkat libido total dan semua domain aspeknya antara sebelum dan sesudah menggunakan aromaterapi jasmine sambac ( $p$ value $\leq 0,05$ ).

Berdasarkan hasil penelitian dapat disimpulkan bahwa aromaterapi jasmine sambac berpengaruh signifikan dalam meningkatkan total libido, termasuk 6 domain aspeknya, pada akseptor suntik DMPA di PMB Aini Kabupaten Kudus.

Salah satu cara untuk mengatasi masalah penurunan libido adalah dengan menggunakan aromaterapi jasmine. Aromaterapi didefinisikan sebagai aromaterapi yang menggunakan lilin aromatik yang diekstrak dari tumbuhan dan bunga-bungaan berupa aromaterapi yang harum dan menyenangkan yang dapat meningkatkan kesehatan. Aromaterapi merupakan cara efektif dan lembut untuk meningkatkan kesehatan tubuh dan untuk relaksasi. Aroma lilin ini akan memicu terjadinya reaksi dalam indera penciuman yang kemudian mengirimkan pesan-pesan tersebut kepada otak sehingga menimbulkn efek relaksasi yang positif yang dapat membangkitkan gairah seksual (Dewi, 2013).

Cara kerja bahan aromaterapi adalah melalui sistem sirkulasi tubuh dan sitem penciuman dimana bau merupakan suatu molekul yang mudah menguap apabila masuk ke rongga hidung melalui pernafasan kemudian akan diterjemahkan oleh otak sebagai proses penciuman. Melalui penghirupan sebagai molekul akan masuk ke paru kemudian molekul aromatik akan diserap oleh lapisan mukosa pada saluran pernafasan, baik pada bronkus atau pada cabang halus (bronchiole) dan terjadi pertukaran gas di dalam alveoli. Molekul tersebut akan diangkat oleh sistem sirkulasi darah di dalam paru. Pernafasan yang dalam akan meningkatkan jumlah bahan aromatic yang ada ke dalam tubuh (Putri et al., 2018).

Aromaterapi yang digunakan dalam penelitian ini adalah aromaterapi jasmine sambac. Aromaterapi jasmine ini dapat mengatasi penurunan gairah seksual (libido), dikarenakan aroma bunga jasmine ini mengandung khasiat anti depresif yang dapat membangkitkan gairah seksual. Lilin dengan aromaterapi jasmine sangat bermanfaat untuk memberikan kenyamanan dan relaksasi sehingga dapat meningkatkan libido (Blue, 2007).

Aromaterapi jasmine memiliki kandungan senyawa utama linalool yang berfungsi sebagai antidepresan. Linalool membuat system syaraf pusat dan kelenjar pituitary meningkatkan hormon endorphine. Hormon endorphine adalah hormon yang dapat memberikan efek stimulasi, senang/bahagia, keseimbangan, dan relaksasi pada pikiran dan fisik tubuh. Efek inilah yang dapat membangkitkan gairah seksual pada seseorang. Selain itu, aromaterapi jasmine ini memiliki aroma yang sedative, sehingga dapat membangkitkan gairah seksual, menenangkan dan melegakan (Koensoemardiyah, 2010).

Saat lilin aromaterapi jasmine dihidupkan, bau dari aromaterapi langsung dapat dirasakan. Responden merasakan rileks karena aroma jasmine yang dihirup bekerja pada gelombang otak yang dapat memengaruhi suasana hati serta fikiran menjadi tenang dan nyaman sehingga dapat memengaruhi libido seseorang sesorang yang mengalami penurunan gairah seksual (Suprijati, 2014).

Pada penelitian ini tidak melihat faktor-faktor lain yang memengaruhi tingkat libido responden, seperti usia, lama pemakaian DMPA, dan hubungan pernikahan dengan suaminya. Namun beberapa faktor sudah dikontrol dengan penetapan kriteria responden untuk lebih menghomogenkan sampel.

\section{KESIMPULAN DAN SARAN}

Aromaterapi jasmine sambac berpengaruh signifikan dalam meningkatkan total libido, termasuk 6 domain aspeknya, pada akseptor suntik DMPA di PMB Aini Kabupaten Kudus, dimana rata-rata peningkatan yang paling banyak adalah pada domain nyeri, dan yang paling sedikit rata-rata peningkatnnya adalah pada domain gairah. Bagi akseptor suntik DMPA yang mengalami efek samping 
penurunan libido dapat menggunakan lilin aromaterapi jasmine sambac untuk mengatasinya. Peneliti selanjutnya diharapkan melakukan penelitian dengan memperhatikan faktor lain yang mempengaruhi penurunan libido.

\section{REFERENSI}

Annisa Aurum Mahardika, Sri Nadya Saanin, H. P. (2016). Pengaruh Aromaterapi Jasmine (Jasmine Officinale) Terhadap Pemendekan Waktu Reaksi Sederhana Laki-laki Dewasa.

Batlajery, J., Hamidah, H., \& Mardiana, M. (2015). Penggunaan Metode Kontrasepsi Suntikan Dmpa Berhubungan Dengan Disfungsi Seksual Wanita Pada Akseptor Kb Suntik. Jurnal IImu Dan Teknologi Kesehatan, 2(2), 49-56. http://www.ejurnal.poltekkesjakarta3.ac.id/Index.p $\mathrm{hp} / \mathrm{JITEK} /$ article/view/46

Blue, F. (2007). Aromatherapy for SAD. December.

C.W., W., L.-M., W., H., S., A.O., M., J., B., \& M., W. (2010). Prevalence of sexual dysfunction and impact of contraception in female German medical students. Journal of Sexual Medicine, 7(6), 21392148. http://0ovidsp.ovid.com.wam.city.ac.uk/ovidweb.cgi?T=JS \&PAGE=reference\&D=emed9\&NEWS=N\&AN=20 10356239

Damailia, H. T., Magelang, P. K., \& Semarang, P. K. (n.d.). Hubungan Lama Pemakaian KB Suntik DMPA ( Depo Medroxyprogesterone Acetate) Dengan Penurunan Libido Pada Akseptor KB DMPA.

Dewi, a. P. (2013). Aromaterapi Lavender Sebagai Media Relaksasi. E-Jurnal Medika Udayana. http://ojs.unud.ac.id/index.php/eum/article/downlo $\mathrm{ad} / 4871 / 3657$

Koensoemardiyah, 2010. (2010). Judul Buku: A to Z Minyak Atsiri untuk Industri Makanan, Kosmetik, dan Aroma Terapi Pengarang: Koensoemardiyah S. Penerbit: Andi Publisher Tahun Terbit: ISBN: Tebal : xi + 78 Halaman.

Lestariningsih, S., Martini, \& Weliyati. (2017). Analisis Penggunaan Metode Kontrasepsi Suntikan DMPA Dengan Disfungsi Seksual. Kesehatan Metro Sai Wawai, X(1), 1-4.

Meyer, B. A. (n.d.). How to Use Essential Oils to Reboot your Mood, Energy, Sleep and Libido.

Pratama, N. I. A., \& Pusparini, P. (2019). Perbandingan disfungsi seksual antara perempuan pengguna kontrasepsi oral dan kontrasepsi suntik. Jurnal Biomedika Dan Kesehatan, 2(3), 124-129. https://doi.org/10.18051/jbiomedkes.2019.v2.124129

Putri, M. F. E. P., Murtaqib, \& Hakam, M. (2018). Pengaruh relaksasi aromaterapi jasmine terhadap kualitas tidur pada lansia di Karang Werdha (The effect of jasmine aromatherapy relaxation towards sleeping quality for elderly at elderly association). E-Jurnal Pustaka Kesehatan, 6(3), 461-468. https://jurnal.unej.ac.id/index.php/JPK/article/view/ 11745

Royhanaty, I. (2017). Penurunan Tingkat Fungsi Seksual Sebagai Salah Satu Efek Samping Pemakaian Kontrasepsi Dmpa Jangka Panjang. Jurnal SMART Kebidanan, $3(2), \quad 26$. https://doi.org/10.34310/sjkb.v3i2.60

Sagita, Y. D., \& Martina. (2020). Pemberian Aroma Terapi Lavender untuk Menurunkan Intensitas Nyeri Pemberian Aroma Terapi Lavender untuk Menurunkan Intensitas Nyeri Persalinan. Wellness and Healthy Magazine, 2(1), 187-192. https://wellness.journalpress.id/wellness\%0Ahttps: //wellness.journalpress.id/wellness/article/view/v1i 218wh

SDKI. (2018). Survey Demografi dan Kesehatan Indonesia. Survei Demografi Dan Kesehatan Indonesia. https://doi.org/0910383107 [pii]|r10.1073/pnas.0910383107

Suprijati. (2014). Efektivitas Pemberian Aromaterapi Untuk Menurunkan Kecemasan Ibu Hamil Trimester lii Dalam Persiapan Menghadapi Persalinan Di Bidan Praktek Mandiri Suprijati Desa Bagi Kecamatan/ Kabupaten Madiun. Journal of Chemical Information and Modeling, 2(9), 58-65.

Triloka Wulandari, D., \& Januriwasti, D. E. (n.d.). Icasha010 Depo Medroksi Progesteron Asetat (Dmpa) Increases Body Mass Index of Acceptors But Decreases Their Libido. 81-85.

WHO. (2016). Rekomendasi Praktik Terpilih pada Penggunaan Kontrasepsi. Diadaptasi Dari Buku "Selected Practice Recommendations for Contraceptive Use" Third Edition 2016, 1(1), 72.

Yosin, E. P., Mudigdo, A., \& Budihastuti, U. R. (2016). Effect of Hormonal Contraceptive on Sexual Life, Body Mass Index, Skin Health, and Uterine Bleeding, in Women of Reproduction Age in Jombang, East Java. Journal of Maternal and Child Health, 01(03), 146-160. https://doi.org/10.26911/thejmch.2016.01.03.02

Zettira, Z., \& Nisa, K. (2015). Analisis Hubungan Penggunaan Kontrasepsi Hormonal dengan Disfungsi Seksual pada Wanita. Majority, 4(7), 103-108. 